\title{
Llansol com Viveiros de Castro
}

\author{
SÉrgio Medeiros \\ Univesidade Federal de Santa Catarina
}

RESUMO: NO LIVRO ONDE VAIS, DRAMA-POESIA?, DA ESCRITORA PORTUGUESA MARIA GABRIELA LLANSOL, O POEMA PASSA E ESCAPA DA POETA, NÃO SE DEIXANDO VER SENÃO RAPIDAMENTE. NA MITOLOGIA AMERÍNDIA, O OUTRO, O INUMANO, PERMANECE E SE DEIXA ADMIRAR, MAS ALGO TAMBÉM "PASSA" E SE PERDE, NESSA TROCA INESPERADA DE OLHARES. ESTE ARTIGO DISCUTE AS RELAÇÕES POSSÍVEIS ENTRE A OBRA DE LLANSOL E O PENSAMENTO INDÍGENA AMAZÔNICO, ESTUDADO PELO ANTROPÓLOGO EDUARDO VIVEIROS DE CASTRO.

ABSTRACT: IN ONDE VAIS, DRAMA-POESIA?, BY PORTUGUESE WRITER MARIA GABRIELA LLANSOL, THE POEM (THE INHUMAN) SURPASSES AND ESCAPES THE POET'S EYE; IT IS ONLY BRIEFLY SEEN. IN AMERINDIAN MYTHOLOGY, THE "OTHER" (THE INHUMAN) PAUSES TO BE ADMIRED, EVEN THOUGH SOMETHING IS LOST IN THIS EXCHANGE OF GAZES. THIS ARTICLE DISCUSSES THE POSSIBLE RELATIONS BETWEEN LLANSOL'S WORK AND THE AMAZONIC MIND AS STUDIED BY BRAZILIAN ANTHROPOLOGIST EDUARDO VIVEIROS DE CASTRO.

PALAVRAS-CHAVE: MARIA GABRIELA LLANSOL; POEMA; MITOLOGIA AMERÍNDIA; EDUARDO VIVEIROS DE CASTRO.

KEY-WORDS: MARIA GABRIELA LLANSOL; POEM; AMERINDIAN MYTHOLOGY; EDUARDO VIVEIROS DE CASTRO. 


\section{criança ignora se a sua canção terá qualquer utilidade. Nem sequer sabe se o poema, de algum modo, a ouve. \\ Conbecer é personificar, tomar o ponto de vista daquilo que de-ve ser conbecido-}

Eduardo Viveiros de Castro

No seu livro Être singulier pluriel, o filósofo francês Jean-Luc Nancy define, nas páginas iniciais, o conceito de compaixão. Segundo Nancy, a compaixão (com-paixão) é contágio, ou contato do ser com outro em meio a um tumulto, uma desordem. A compaixão, enquanto estado intenso de ligação, não é, assim, altruísmo nem identificação, mas perturbação e inquietação.

Contudo, essa ligação intensa, descrita por ele, seria, antes, contigüidade e não contato. Nancy esclarece que a ligação, no caso, não implica continuidade nem conexão. Segundo o filósofo, a lei do toque (o que comove) é a separação, uma vez que pressupõe a heterogeneidade das superfícies que se tocam uma na outra. Ou seja, o contato estaria, nesse estágio, além da completude e do vazio, como está, já vimos, além da conexão e da desconexão.

Podemos falar então de coexistência do ser com o outro, empregando o "com" para aludir a isso: estar com, estar junto, separadamente. Este artigo se propõe, assim, a imaginar a coexistência da escritora portuguesa contemporânea Maria Gabriela Llansol, falecida em 2008, com o antropólogo brasileiro Eduardo Viveiros de Castro, um dos mais importantes estudiosos atuais do perspectivismo ameríndio. Não há outro segredo neste ensaio senão essa coexistência, que não é, diga-se de uma vez por todas, um segredo, mas sim um estar com, simplesmente, já pressentido por outros. ${ }^{1}$ Adianto apenas que em suas respectivas obras esses autores propõem e discutem a contigüidade (separação) entre o humano (o xamã) e o inumano (o outro), entre o eu (a poeta) e o não-eu (o poema), de maneira que se pode falar da presença da compaixão, tal como definida por Nancy, em seus textos.

1 A idéia de escrever este ensaio surgiu de uma conversa, no primeiro semestre de 2009, em Belo Horizonte, com a professora Maria Inês de Almeida, coordenadora do Núcleo de Pesquisas Transdisciplinares Literaterra (UFMG). 
Maria Gabriela Llansol afirma que o poema passa rápido, no livro Onde vais, drama-poesia?, então, para captá-lo (ou caçá-lo, termo caro a Viveiros de Castro), é preciso ser veloz. Também afirma, no mesmo capítulo dessa obra, que é inconcebível não haver um corpo humano (animal bumano) "que o não suporte". Ao colocar aqui Llansol com Viveiros de Castro, vou indagar se, para o poema, não seria igualmente inconcebível não haver um corpo inumano (animal animal) "que o não suporte". Assim, o poema encontraria como suporte sempre um humano e um inumano na sua passagem veloz, pois o poema passa de um lado para o outro, indo além dos fins do homem, ao mesmo tempo voz do homem e canto do animal. "Impossível dizer-lhe que espere", afirma a escritora portuguesa, "que não consigo escrever à sua velocidade, que se repita ou volte a dizer (quando, de facto, nada diz) o que estava a dizer. Passa é seu fato fundamental”.(LLANSOL, 2000: 17)

Se o poema não nos espera e nos ignora, há quem esteja, segundo a mitologia amazônica, à nossa espera, a fim de nos olhar primeiro. O que dizer do olhar do outro (metáfora?, poema reduzido a uma só imagem?), que vem do outro lado, do inumano, e atravessa o humano? Ou do olhar que, em resposta, ou mesmo antes da resposta, lançamos deste lado para o outro lado? Há de fato um olhar veloz que sempre passa, ou nos atravessa, na teoria de Viveiros de Castro. Esse olhar inumano, que buscarei circunscrever aqui, e o poema de Llansol, mencionado atrás, caminham talvez na mesa velocidade.

No livro A inconstância da alma selvagem, Viveiros de Castro discute o conceito de perspectivismo (ou o complexo conceitual do perspectivismo ameríndio), que poderia ser definido grosso modo como um processo de pôr-se no lugar de outro. (Ou pôr o lugar no outro, dar o lugar ao outro...). O perspectivismo, geralmente associado ao xamanismo, seria não apenas um fenômeno amazônico, mas também panamericano. Segundo uma das teses do perspectivismo indígena, na origem do mundo os animais eram gente, de tal modo que, embora hoje eles pareçam ter-se afastado definitivamente do mundo da cultura, ainda se vêem a si mesmos como humanos. É assim, com olhos humanos, que ele nos miram quando nos deparamos com um deles, no meio da floresta.

A partir desse fato se percebe, em qualquer discussão contemporânea dos mitos brasileiros, a importância do olhar e, sobretudo, o quanto é cru- 
cial, para o perspectivismo, a questão da velocidade do olhar, assunto que me proponho a tratar, a seguir, relacionando esse tema mitológico à velocidade do poema, um tema de Llansol. A poeta portuguesa pede ao poema que se detenha, mas não é atendida. Vemos então se esboçar um conflito de interesses, envolvendo o poema veloz e a poeta morosa, ou não tão veloz quando o próprio poema. A poeta fica com fragmentos, sobras, a outra parte do poema adiantou-se e foi embora. A poeta gostaria de correr ao lado do poema, acompanhando-o, mas essa contigüidade é problemática, advém o tumulto. Não poderiam os dois, o poema e a poeta, simplesmente se cruzarem, vindo ambos de direções opostas, como nos mitos amazônicos que narram o humano e o inumano frente a frente na floresta? Mas isso tampouco anularia a impossibilidade do contato, a heterogeneidade das partes. A poeta e o poema estariam, aparentemente, no livro de Llansol, competindo um com o outro e reatualizando a mítica corrida que Aquiles disputou com a tartaruga, tão comentada, como sabemos, por Lewis Carroll e Jorge Luis Borges, dois mestres dos encontros impossíveis, do contato sem contato, da separação infinita.

$\mathrm{O}$ conflito de interesses (sem desconsiderar a perturbação, a inquietação que qualquer contato pressupõe, segundo Nancy) existe igualmente no perspectivismo ameríndio, que pressupõe, como seu cerne, o encontro do índio com o inumano, que caminham um em direção ao outro. Temos aí um exercício da com-paixão, e talvez, nessa caso específico, também a exacerbação do tumulto e da desordem, o que poderia levar, naturalmente, penso eu, a uma não-com-paixão. A esse respeito, cabe ressaltar que, segundo a exposição de Viveiros de Castro, o encontro ou intercâmbio de perspectivas é processo perigoso. E o antropólogo acrescenta: é uma arte política, uma diplomacia. A troca de olhares velozes, selando o encontro (a contigüidade) daqueles que se aproximam um do outro, poderia, enfim, exacerbar conflitos imemoriais.

Numa entrevista recente, o antropólogo brasileiro, ao mencionar um dos "traumas típicos" do índio, que consiste em deparar na mata com um bicho que não é bicho, mas gente, afirma: "Quando um bicho no mato falar contigo, não responda, a não ser que você queira deixar o socius para entrar no mito... Outro conselho comum: você tem que olhar primeiro para o bicho, antes de o bicho olhar para você. Porque se ele olhar para você antes de você olhar para ele (não é ver, é olhar), você é capturado pela potência subjetiva 
dele, você perde sua soberania, está nas mãos dele". ${ }^{2}$ Ou seja, como Viveiros de Castro explica em outra passagem dessa entrevista, tudo é gente, porém tudo não pode ser gente ao mesmo tempo, uns para os outros, daí esse combate pelo ponto de vista. (Lembrando o que disse Llansol sobre o poema, eu seria levado a afirmar, aproveitando essa fala do antropólogo, que a poeta e o poema não poderiam revelar-se plenos ao mesmo tempo: primeiro, o poema passa, depois, a poeta escreve, recolhendo seus restos, ou seu traço.) A lei da contigüidade, que formulo agora, não permite que dois seres diferentes se toquem, nem que eles ocupem ao mesmo tempo o mesmo espaço, pois estão separados, em meio ao tumulto do contato intenso... sem contato.

Mas, fato decisivo que é preciso destacar, neste possível diálogo de Viveiros de Castro com Llansol, é que a troca de perspectivas, conflituosa como é, ou poderia vir a ser, implica um modo de conhecer, um ideal de conhecimento, assim como o registro da passagem do poema, o anúncio da sua fuga, é o exercício poético possível, a obra que a poeta elabora ao perder, senão tudo, quase tudo, no ato de ver/ouvir (pouco) o poema apressado. Gostaria de especificar melhor a natureza do olhar poético e xamânico, envolvido em ambas as experiências.

No caso do perspectivismo ameríndio, o olhar do índio não busca a objetivação, assim a forma do outro, que ele encontra alhures, fora da aldeia, já não é a coisa. Na exposição de Viveiros de Casto, lemos: "Conhecer é personificar, tomar o ponto de vista daquilo que deve ser conhecido -- daquilo, ou antes, daquele; pois o conhecimento xamânico visa um 'algo' que é um 'alguém', um outro sujeito ou agente. A forma do Outro é a pessoa." (Viveiros de Castro, 2002: 358). O xamã se torna, assim, a figura de referência para o perspectivismo e é por meio de seu agir (ele cruza fronteiras e estabelece relações sociais com os outros seres) que se discute o que o antropólogo chama de personificação (é preciso personificar para saber), a qual é uma arte política: "Pois a boa interpretação xamânica é aquela que consegue ver cada evento como sendo, em verdade, uma ação, uma expressão de estados ou predicados intencionais de algum agente". (Ibidem, 359) O objeto, agente dessa ação, é sempre sujeito, e deve ser interpretado como tal, uma vez que se está

2 Entrevista publicada em 23 de maio de 2008, sob o título "Uma boa política é aquela que multiplica os possíveis", no site de arte e cultura Centopeia. 
estabelecendo com ele uma relação social. (O outro é mais do que uma metáfora, é um poema vivo, de carne e osso, ouso acrescentar.)

A conclusão que gostaria de destacar, e usar como referência para reintroduzir a velocidade do poema que não espera e atrás do qual o poeta deve ir, é a seguinte: o que uns chamam de "natureza" poderá ser a "cultura" do outro, o que, se adotarmos também o pensamento perspectivo para pensar a experiência ocidental e não apenas a indígena, serve seguramente para reorientar as relações entre humanos e não-humanos, uns não sendo mais simples (ou tão-somente) metáfora do outro.

O poema sempre encontra um humano, afirma Llansol em Onde vais, dramapoesia?, porém não o reconhece. "Não me reconhece", ela insiste. A poeta, com um "foco de luz libidinal aceso sobre o lugar" onde escreve, inundada de "puro luar libidinal", tenta estabelecer com o poema, o inumano, mais do que simples relação social, é com-paixão. O poema que passa não possui a ferocidade do outro que, num recesso da floresta, como diria Viveiros de Castro, pára e olha para o índio que deixou-se captar por esse olhar, ao encontro do qual ele caminhou, consciente ou inconscientemente. Mas o poema, nessa situação, "Passa como expressão de uma alegria pura", não re-conhecendo o outro, apesar disso, ou por isso mesmo, esse complicado contato o afeta muito, é fonte de perturbação, inquietação, segundo as palavras usadas por Nancy para descrever a com-paixão.. A poeta o vislumbra como um colar, um adereço que ela mesma desejaria usar (consentida submissão, tentativa de transformar a contigüidade em contato ou unidade), como um laço que espontaneamente ela colocaria no próprio pescoço, unindo-se ao poema e correndo atrelada a ele para sempre: o colar, porém, se parte (e a alegria de que fala a poeta é, paradoxalmente, essa impossibilidade de submissão, subitamente revelada: o contato é somente contigüidade), o poema e a poeta, juntos, porém não unidos, então vêem, de perspectivas distintas, "as pérolas tilintando a rolar pelo chão".

Torna-se necessário citar o fragmento, no qual se diz que o poema:

não nasce de uma falta

ou de uma carência, nem da falta de uma carência. Passa como expressão de uma alegria pura, como um colar que se quebra, e vê as suas pérolas tilintando a rolar pelo chão da vOz, 
velozes por partir do lugar onde estavam ligadas por uma força unitiva de grande posse. (Llansol, 2002: 18)

O que vemos nesse fragmento é um estágio intenso de ligação, e, sobretudo, um contato sem contato, no seu tumulto e inquietação jubilosa. É uma com-paixão que não prevê nenhum tipo de posse, mas a separação.

A idéia de desunião e perda que encontramos nessa "alegria pura" (e certamente efêmera), quando o poema e o poeta momentaneamente quase se emparelham na sua pista de corrida (a poeta sabe finalmente que o contato é contigüidade), existe tal qual na experiência relatada nos mitos ameríndios e, particularmente, nas viagens xamânicas, nas quais o índio se separa da tribo e da própria identidade primeira para mergulhar no, ou aproximar-se do, inumano. Só que, nesse momento do encontro sobrenatural e/ou poético, o outro (já pressentimos) é potencialmente capaz de "devorar" sem nenhuma compaixão o sujeito, despojando-o de sua prerrogativa humana e fazendo dele, em conseqüência, um inumano. (O humano poderá, igualmente, dependendo das circunstâncias, devorar ou apossar-se do inumano.) Ou seja, são muitas as separações, as perdas implicadas nessa experiência radical que descrevemos, apoiados na antropologia contemporânea.. Também a experiência poética é radical na literatura de Llansol e o "estar com" revela-se, aí, mais complexo e diversificado do que imaginamos, embora, em nenhum momento, pareça implicar a violência descrita nos mitos.

Num outro livro da autora, Amigo e amiga: curso de silêncio de 2004, lemos que "o texto impunha-se -- autônomo --, não dependente do seu humano", ou seja, parece que o texto poético, que estamos perseguindo junto com a escritora neste ensaio, ora depende de um humano, ora é inteiramente independente, podendo tornar-se um poema autônomo, uma prosa "não inserível", expressão usada pela narradora. É uma idéia que deveria ser confrontada com a evolução do diálogo entre o humano e o outro, segundo o perspectivismo indígena. O outro, como o poema, muitas vezes depende do "seu humano" para revelar-se a nós como gente (como voz, canto, ação), porém, ao mesmo tempo, sabemos que o outro, no começo do mundo, vale dizer, nos relatos cosmogônicos, impôs-se a todos como ser autônomo, pois nesse tempo remoto ele era humano por si só. Segundo narram os mitos, no começo do mundo, todos (homens, bichos, plantas) eram gente, a distinção entre huma- 
nos e inumanos é posterior. Também se poderia dizer que o poema é gente, nesse momento cosmogônico, descrito por Llansol, que parece anteceder a distinção entre poema (não-eu) e poeta (eu), entre natureza (o inumano) e cultura (o humano).

No mesmo fragmento que estamos comentando, Llansol afirma a respeito do homem (do poeta):

\section{Durmo.}

Não creio que o ser humano seja o lugar de convergência do Universo. Falar dele como se fosse o seu umbigo ("sim, é ------") faz-me ver que talvez seja uma tentativa de exaustão da vida.

Este foi o primeiro pensamento claro e distinto, pela manhã.

eu, semelhante e dissemelhan-

te de uma coisa mínima, não sou o centro do Universo. (Llansol, 2005: 204)

Essa certeza, a de não ser o centro, a de não ser o lugar de convergência do Universo (o que, diga-se en passant, leva a poeta buscar ou encontrar os Híbridos e suas metamorfoses), poderia ser ilustrada, talvez, pela concepção ameríndia que suporia, segundo Viveiros de Castro, uma unidade do espírito e uma diversidade dos corpos. Ou seja, a cultura e o sujeito estavam, e ainda estão, segundo os xamãs e os poetas (ambos são grandes especialistas em inversões perspectivas), em todos os lugares e não apenas no homem. "Recordemos", afirma o antropólogo brasileiro, "que, se há uma noção virtualmente universal no pensamento ameríndio, é aquela de um estado originário de indiferenciação entre os humanos e os animais, descrito pela mitologia”. (Viveiros de Castro, 2002: 254)

No contexto dessas perspectivas móveis que estamos comentando, a escritora portuguesa, no mesmo livro Amigo e amiga, observa: "Habitualmente, 
ninguém chama animal a uma ave. A leveza do ovo e o peso de 'animal' não coincidem. O animal/ave é uma incongruência”. (Llansol, 2005: 219) Também para o xamã, no universo do perspectivismo, chamar uma onça, ou alguma ave de rapina, por exemplo, de animal é, de certa maneira, por tudo o que vimos acima, uma incongruência, pois, conforme sua experiência na floresta o demonstra, encontrar o outro é vivenciar o intercâmbio de perspectivas, e, nessa experiência radical, o inumano revela-se humano e vice-versa, num jogo ora jubiloso (para a poeta), ora perigoso (para o xamã), em que conhecer é personificar e inverter papéis, mas disso não se sai sempre incólume, nem sempre a com-paixão dá o tom (o tumulto é então desordem demasiada e ruptura da contigüidade). Enquanto o perspectivismo indígena resiste, às vezes, à alegria pura, ao júbilo de “estar com”, já no poema de Llansol, em troca, verificamos essa com-paixão realizar-se plenamente. Daí a poeta, na sua alegria, no seu júbilo, e talvez também na sua dor, sentir-se, como afirma Llansol, na prosa porosa citada acima, "semelhante e dissemelhante de uma coisa mínima" e não mais (ou nunca mais) o centro do Universo.

Muitas vezes, por isso mesmo, o canto poético está, não no animal humano, que lhe serviria de necessário suporte, mas, como afirma Lhansol, nos "animais animais". Existe um texto, desde sempre à disposição dos poetas, que antecederia a distinção entre cultura e natureza, assim como o poema, tanto na definição de Nancy (dela voltarei a falar) quanto na obra de Llansol, antecede a separação entre prosa e poesia. Depois de afirmar que os animais cantores-de-leitura têm garganta de ouro e uma voz que durará sempre devido à sua estranheza (é remota, abrupta), Llansol declara: "não raras vezes preciso destes animais animais que me transportam nos seus sons, ou ruídos, muito inocentes, coerentes e antigos sem que o texto, para eles, constitua qualquer carga". (Idem, 230) Esses animais animais também lêem, cantam ou declamam o "fluido inesquecível", como os animais humanos. Temos aqui uma personificação e uma mudança de perspectiva, que implica entrar em contato com algo remoto e jubiloso, já que o ouvido da poeta, como o do xamã, pôde adaptar-se ao inumano, à estranheza e à inversão, ou distorção, do "sentido da melodia". Nesse instante, o poema é realmente inumano, e vai carregado pelo animal que o conseguiu captar de alguma maneira. Por isso o poema é o outro, é gente no sentido mitológico, nem inteiramente humano nem unicamente inumano. A gente dos mitos poderia dizer, citando talvez Nancy: "Eu sou plural". 
Voltando à passagem de Onde vais, drama-poesia?, na qual se fala em "captar o poema que passa rápido", início deste diálogo de Llansol com Viveiros de Castro, a escritora também afirma, ali, que ler é ser chamado a um combate, ou seja, a um drama: "Um poema que procura um corpo sem-eu, e um eu que quer ser reconhecido como seu escrevente". (Llansol, 2000: 18) O poema é o inumano humano que busca um humano inumano (o poeta-leitor/ o poetatradutor), numa inversão de perspectivas semelhante àquela que ocorre entre o xamã e o outro, no âmago da floresta, conforme narra a mitologia ameríndia: lá ocorre um combate ou drama, envolvendo pontos de vista divergentes e, possivelmente, dependendo da exacerbação dos ânimos e da força política de cada parte, se igual ou desigual, troca definitiva ou temporária de papéis e não apenas reconhecimento mútuo.

$\mathrm{Na}$ narração de Llansol, no livro citado acima, anuncia-se, como solução para o impasse, para a crise da com-paixão, "Fugir ao destino do vate. Fugir à mediocridade da autobiografia". (Idem, ibidem). Entendo que uma nova perspectiva se abriu ao texto literário, alterando definitivamente o papel do autor, o do leitor e o do poema, nesse drama no qual combatem o inumano e o humano, o eu e o não-eu. O texto de Llansol nasceu aí, exatamente, e o dramático, neste caso, segundo a estudiosa Maria Esther Maciel, que alude na sua leitura de Onde vais, drama-poesia? a uma subjetividade polifônica (os "eus" se combatem entre si), "furta-se obviamente à condição de 'gênero' literário para se tornar um exercício complexo de 'outridade', a que o drama-poesia llansoliano vai conferir novos matizes". ${ }^{3}$ Entre esses possíveis novos matizes, apontei aqui, ou sugeri, sua vertente perspectiva, num diálogo com a aventura xamânica (igualmente exercício complexo de outridade), estudada pelo antropólogo Viveiros de Castro.

$$
* * *
$$

A poesia é a negatividade, afirma o filósofo Jean-Luc Nancy, em Résistance da la poésie, ou "uma unidade indeterminada de um conjunto de qualidades

3 MACIEL, 2004, p. 137. (Ao discutir a linguagem híbrida dessa obra de Llansol, a crítica enumera, ou tenta fazê-lo, sua diversidade de expressão, destacando, dentre as formas diversas que convivem no livro, poemas, fragmentos em prosa, excertos de diário, diálogos, extratos ensaísticos, frases soltas, descrições.) 
que não estão reservadas ao tipo de composição chamado "poesia"' (Llansol, 2005: 9-10), a poesia está no verso, claro, mas também na prosa e alhures. No sentido figurado, está numa produção natural, ou no caráter ou beleza de uma pessoa etc. Assim, ela é por essência mais do que a própria poesia, e algo diferente da poesia. Isso é a negatividade da poesia, ela pode ser o seu contrário e pode encontrar-se onde não existe propriamente poesia. A poesia, em suma, em razão dessa negatividade intrínseca, não coincide consigo mesma. Talvez a poesia resida justamente nessa "impropriedade substancial", conforme propõe Nancy no ensaio citado, e por isso ela não se identifica com qualquer gênero ou modo poético.

Parece-me que a experiência do xamã amazônico e a da escritora portuguesa contêm igualmente uma negatividade, uma renúncia persistente a deixar a vida e a arte identificarem-se só com o humano ou só com o inumano. A vida é um conjunto de perspectivas móveis, onde a própria oposição entre o humano e o inumano, entre o eu e o não-eu, é negada como oposição. Lembra Nancy, a esse propósito, que, para a poesia, na medida em que ela não aceita ser circunscrita a um gênero de discurso e questiona distinções, a fórmula "filosofia versus poesia" não constitui mais uma oposição. "Uma faz a dificuldade da outra", conclui o filósofo. "Juntas, são a própria dificuldade: de fazer sentido". (Idem, 12) Diria que a diferença da poesia e da antropologia, ou da poesia e das artes plásticas etc., não pode resolver-se numa distinção, numa oposição entre ficção e ensaio, texto e imagem, ou, retomando a discussão anterior, entre a cultura e a natureza, entre o humano e o inumano, o eu e o não-eu, a literatura e a não-literatura etc. Pois, concluindo, a poesia é, como sabemos, também a negatividade, tanto na obra de Llansol quanto nos mitos amazônicos. Por isso a poesia passa e o poeta fica, com muito ou pouco nas mãos.

\section{Referências Bibliográficas}

LLANSOL, Maria Gabriela. Onde vais, drama-poesia? Lisboa: Relógio d'Água, 2000 - Amigo e amiga: curso de silêncio. Lisboa: Assírio \& Alvim, 2005

MACIEL, Maria Esther. A memória das coisas: ensaios de literatura, cinema e artes plásticas.

Rio de Janeiro: Lamparina, 2004.

NANCY, Jean-Luc. Être singulier pluriel. Paris: Éditions Galilée, 1996 
.Resistência da poesia. Lisboa: Vendaval, 2005

VIVEIROS DE CASTRO, Eduardo. A inconstância da alma selvagem. São Paulo: Cosac \& Naify, 2002.

. "Uma boa política é aquela que multiplica os possíveis", in Centopeia (http:/ / www.centopeia.net) (Acesso em 22 de junho de 2009.) 